CERÁMICA Y LÍTICA COMO INDICADORES DE CAMBIO Y PERSISTENCIA TECNOLÓGICOS DURANTE EL PERÍODO DE CONTACTO EN EL PONIENTE DE LA CUENCA DE MÉXICO

CERAMICS AND LITHICS AS INDICATORS OF TECHNOLOGICAL CHANGE AND PERSISTENCE DURING THE CONTACT PERIOD ON THE WEST SIDE OF THE MEXICO BASIN

David Arturo Muñiz García

Kimberly Sumano Ortega

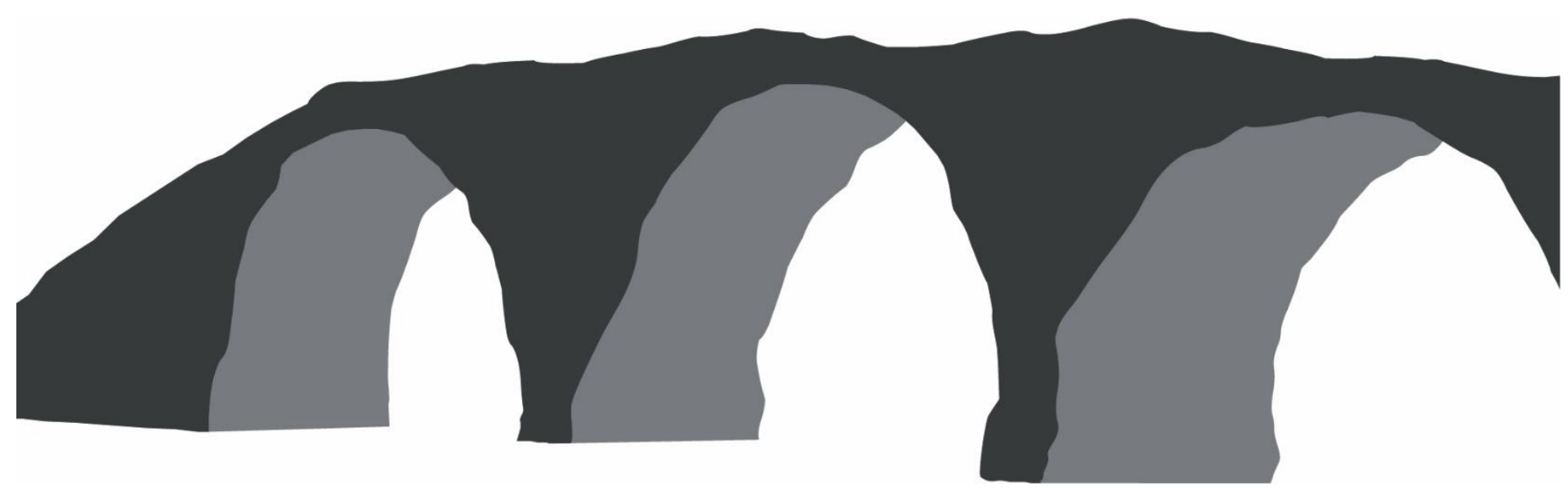




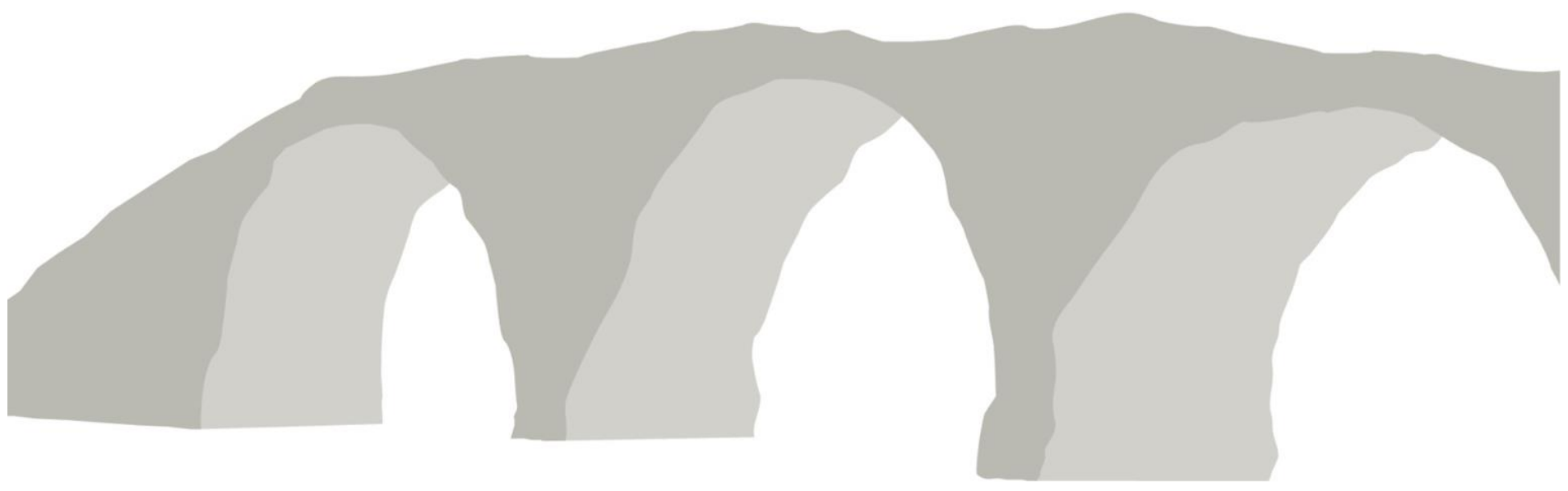

Data de recebimento: 05/09/2017.

Data de aceite: 25/09/2018. 


\title{
CERÁMICA Y LÍTICA COMO INDICADORES DE CAMBIO Y PERSISTENCIA TECNOLÓGICOS DURANTE EL PERÍODO DE CONTACTO EN EL PONIENTE DE LA CUENCA DE MÉXICO
}

\section{CERAMICS AND LITHICS AS INDICATORS OF TECHNOLOGICAL CHANGE AND PERSISTENCE DURING THE CONTACT PERIOD ON THE WEST SIDE OF THE MEXICO BASIN}

\author{
David Arturo Muñiz García ${ }^{1}$ \\ Kimberly Sumano Ortega ${ }^{2}$
}

\begin{abstract}
RESUMEN
Se ha asumido que el arribo del mundo occidental a Mesoamérica significó un cambio cultural, reflejado en la transformación del inventario artefactual de las comunidades. Sin embargo, la persistencia en el uso de ciertos materiales como la lítica y la cerámica, a pesar de contar con otras opciones tecnológicas, nos permite intuir procesos de largo aliento en la apropiación del entorno y las condiciones socioeconómicas. En el presente trabajo se muestra el uso combinado de materiales prehispánicos y coloniales en un pequeño asentamiento del posclásico en la Cuenca de México, en donde parece que la presencia de un cambio tecnológico en los materiales arqueológicos no necesariamente significó un cambio cultural a pesar de localizarse en la transición del periodo prehispánico a la colonia.
\end{abstract}

Palabras clave: Cambios y Persistencias Culturales, Tecnología, Postclásico, Cuenca de México.

RESUMO

Supõe-se que a chegada do mundo ocidental à Mesoamérica significou uma mudança cultural, refletida na transformação dos inventários de artefatos nas comunidades. No entanto, a persistência no uso de materiais como o lítico e o cerâmico, apesar de possuírem outras opções tecnológicas, permitem intuir processos de longo prazo na apropriação do meio ambiente e condições socioeconômicas. O presente trabalho mostra o uso combinado de materiais pré-hispânicos e coloniais em um pequeno assentamento pós-clássico na Bacia do México, onde parece que a presença de uma mudança tecnológica nos materiais arqueológicos não significou uma mudança cultural, apesar de estar localizada na transição do período pré-hispânico para a colônia.

Palavras-chave: Mudança e Persistência Cultural, Tecnologia, Posclasico, Bacia de Mexico.

\footnotetext{
${ }^{1}$ Centro INAH Michoacán. Hacienda de la Flor \#64 Villa Quietud, Coyoacán Ciudad de México c.p. 04960, +1 525544427727 davidmunizgarcia@gmail.com. Arqueólogo de la Escuela Nacional de Antropología e Historia y maestro en arqueología por el Colegio de Michoacán, ha participado en distintos proyectos en el centro, occidente y norte de México. https://orcid.org/0000-0001-5219-3738.

${ }^{2}$ University of Texas at El Paso (UTEP). 4141 Westcity ct, El Paso, Texas zip 79901, +1 915 2489126, ksumaoort@miners.utep.edu. Historiadora por la Universidad Nacional Autónoma de México, maestra en arqueología por el Colegio de Michoacán y actualmente en el programa de doctorado de la Universidad de Texas en el Paso. Ha impartido clases a nivel licenciatura y participado en distintos proyectos arqueológicos. https: / / orcid.org/0000-0003-0811-0610.
} 


\section{ABSTRACT}

It has been assumed that the arrival of the western world to Mesoamerica meant a cultural change, reflected in the transformation of the artifactual inventory of the communities. However, persistence in the use of materials such as lithics and ceramics, despite of having other technological options, allows us to interpret long-term processes in the appropriation of the environment and socioeconomic conditions. This work shows the combined use of Prehispanic and colonial materials in a small Postclassic settlement in the Basin of Mexico, where it seems that the presence of a technological change in the archaeological materials did not mean a cultural change despite its temporal association with the transition from the pre-Hispanic period to the colony.

Keywords: Cultural Change and Persistence, Technology, Postclassic, Mexico Basin. 


\section{INTRODUCCIÓN}

Tradicionalmente se ha plateado que el proceso de conquista en Mesoamérica trajo consigo un gran cambio cultural; pero un cambio en aspectos como la tecnología no necesariamente implica una transformación de las condiciones socioeconómicas. Más aun, la persistencia en el uso de algunos materiales podría reflejar la continuidad de ciertas condiciones de vida, como sería el caso del pequeño asentamiento de Tarango al poniente de la Cuenca de México durante el posclásico y la transición hacia la colonia. A partir de las investigaciones arqueológicas de campo y referencias documentales, se observa un cambio tecnológico en la cerámica y la lítica, así como en distintas estrategias de apropiación del espacio, las cuales parecen no haber modificado sustancialmente el modo de vida en este lugar. Se propone que en Tarango es posible observar una persistencia cultural a pesar del cambio tecnológico, producto del proceso de conquista. Lo anterior nos lleva a observar críticamente aquellas narrativas "terminales" que sugieren que la conquista trajo aparejado un gran cambio cultural, y que no cuestionan el proceso de transición, cambio o incluso persistencia, sino que asumen el fin de una época y principio de otra a tábula rasa.

El Proyecto de Prospección y Sondeos Arqueológicos en la Súper Vía Poniente (PSASVP) se inició en diciembre de 2011 con la finalidad de proteger e investigar los vestigios que pudiesen estar en riesgo por la construcción de una nueva autopista urbana al poniente de la Ciudad de México. La Dirección de Salvamento Arqueológico del Instituto Nacional de Antropología e Historia decidió intervenir el área y llevar a cabo un salvamento urbano en un espacio de $5.4 \mathrm{~km}$ lineales de obra, y cerca de $5.5 \mathrm{~km} 2$ de obras alternas, además del área de protección ambiental de la Barranca Tarango, dentro de los límites de las delegaciones Magdalena Contreras, Tlalpan y Cuajimalpa (Figura 1). De este proyecto, dirigido por los arqueólogos David Muñiz y Susana Lam, emana el presente escrito, mostrando algunos de los resultados obtenidos por parte del PSASVP (cuyos trabajos involucran un esfuerzo por interpretar e insertar las evidencias recuperadas en un problema de investigación de amplio alcance). Si bien estamos conscientes de distintas limitaciones interpretativas del artículo, consideramos necesario someter a revisión las evidencias recuperadas y las fuentes consultadas en la búsqueda de iniciar una discusión académica que ayude a entender las dinámicas sociales en el poniente de la cuenca.

En las décadas recientes, el cambio tecnológico ha sido visto como un indicador de las transformaciones culturales, y como uno de los factores determinantes en la variabilidad artefactual del registro arqueológico. Si bien esto parece ser una sentencia positiva, es necesario ser cuidadosos pues la práctica arqueológica puede llevarnos a realizar afirmaciones generalizadoras y, por lo tanto, a dar por sentado una interpretación (Cfr. Schiffer et al., 2001). Un ejemplo de ello son las llamadas "narraciones terminales", como es el caso de la desaparición de grupos nativos en California con el proceso de conquista. Panich (2013: 106) muestra la manera en que sentencias generalizadoras como las de Kroeber y otros autores a principios del siglo XX, llevaron a la creación de un discurso que negaba la presencia de indígenas en la región, mientras que por otro lado los trabajos arqueológicos mostraban una persistencia en la presencia indígena reflejada en el inventario artefactual. De manera más amplia, la aseveración respecto a que la llegada del mundo occidental a América trajo consigo una profunda trasformación cultural parece ser un dicho incuestionable (Charlton \& Fournier, 1993), y por lo tanto una narrativa "terminal" que también es necesario cuestionar. Del mismo modo que en el ejemplo brindado por Panich, la sentencia de que para el período de contacto deberíamos ver, desde la arqueología, un 
gran cambio cultural a través del cambio tecnológico es una narrativa "terminal" que niega de cierto modo la persistencia del mundo indígena.

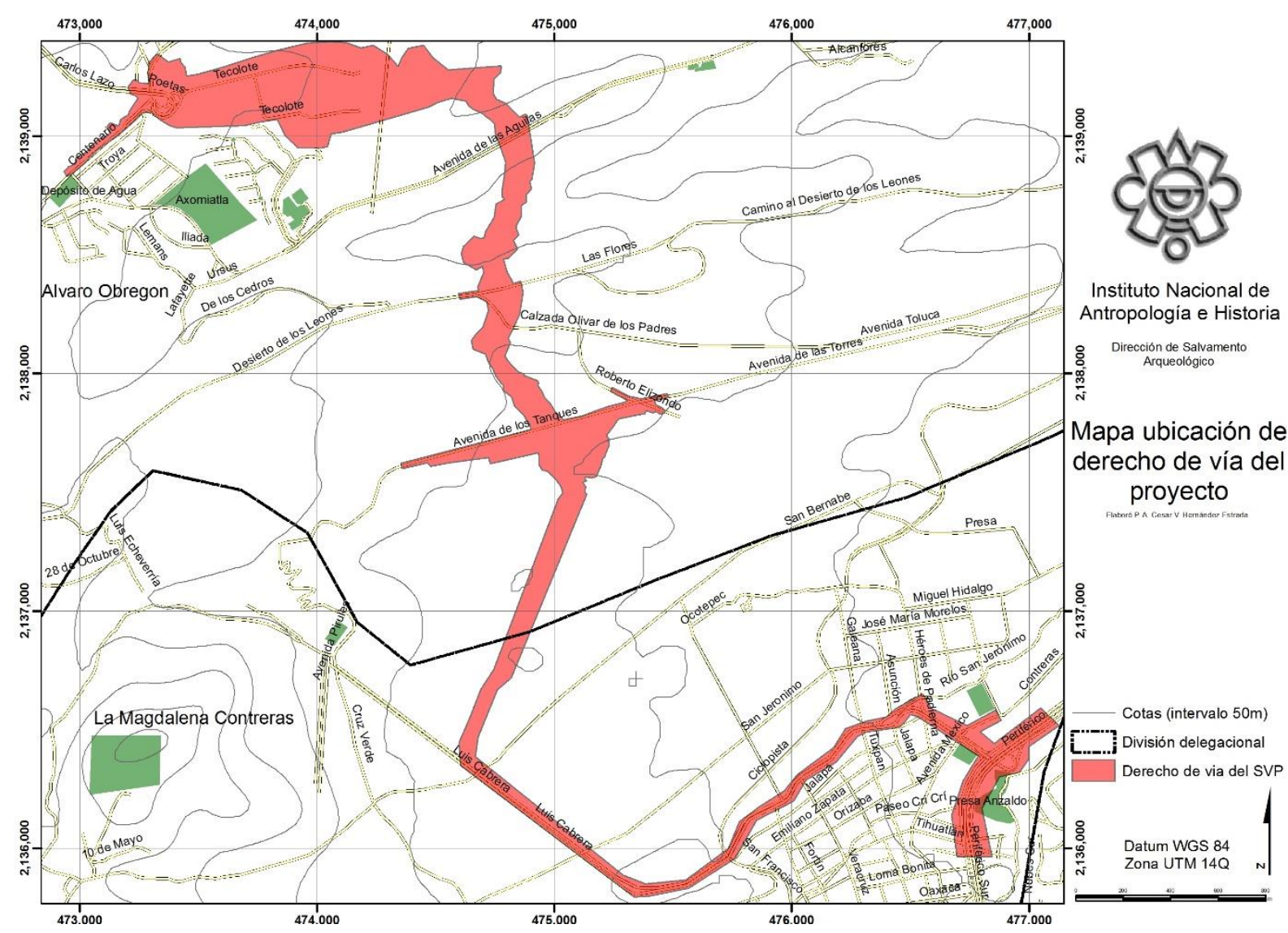

Figura 1: Mapa de ubicación del PPASVP. Elaboró Cesar Hernández.

Durante los trabajos del PSASVP se recuperaron una serie de artefactos arqueológicos que evidenciaban un cambio tecnológico en materiales como la cerámica (por ejemplo, a través de la presencia de mayólica, propia del período colonial y ausente en momentos previos), y la introducción de otros como el hierro y el vidrio, producto del contacto con los europeos. Estos hallazgos se realizaron en el marco de unas construcciones con características de marginalidad (terrazas, canales de riego, unidades domésticas) ${ }^{3}$. Las características ambientales de esta zona no parecieron ofrecer el mejor escenario para vivir, lo cual contrastó con la proliferación de recursos en otras partes de la cuenca. Esta condición de marginalidad pareció coincidir con la información proveniente de fuentes históricas respecto a las características de las poblaciones que habitaron en las cañadas al poniente de la Cuenca de México. Ante esta situación, se abrió el interrogante de por qué contábamos con la presencia de población en este lugar.

Ahora bien, tradicionalmente los trabajos arqueológicos en la región se han centrado en lo monumental y en períodos previos al contacto. Nosotros consideramos que el estudio de lugares como Tarango nos permite

\footnotetext{
${ }^{3}$ En un trabajo anterior (Muñiz \& Sumano 2017) se profundiza en las características del entorno construido y estudios palinológicos, lo cual nos permite asumir que el asentamiento de Tarango habría estado ocupado por poblaciones marginales del posclásico tardío y el inicio del perído colonial. Como ejemplo tenemos una fuerte inversión de trabajo para construir terrazas agrícolas y sistemas de riego, pero de acuerdo con los estudios de polen, el suelo generado siguió siendo pobre y usado casi exclusivamente para el monocultivo de maíz. Las zonas agrícolas estaban ubicadas alrededor de habitaciones no permanentes.
} 
observar los procesos históricos de la Cuenca de México desde la perspectiva de las dinámicas locales. Pero antes de poder aplicar esto, es necesario saber qué características tuvieron las poblaciones que habitaron este lugar, y cuál pudo ser su papel en la dinámica sociocultural en el posclásico tardío y el período colonial temprano. Se propone aportar a la comprensión de esta dinámica a partir del estudio principal de los materiales recuperados, y el poder hacerlo desde el salvamento arqueológico es una oportunidad para mostrar el aporte potencial de esta subdisciplina a la arqueología en general. En nuestro caso, la presencia de lo que pareció ser una larga convivencia entre distintas tecnologías nos llevó a cuestionar la dependencia causal de la trasformación cultural con el cambio tecnológico.

El propósito de este trabajo fue entender el cambio tecnológico al arribo del período colonial y la persistencia en el uso de materiales en Tarango. Durante del desarrollo del PSASVP se observó la convivencia de materiales con distintas tecnologías. La persistencia en el uso de materiales como la lítica y la cerámica, a pesar de contar con otras opciones tecnológicas, nos permite intuir procesos de largo aliento en la apropiación del entorno y las condiciones socioeconómicas de algunas poblaciones indígenas. Aquí mostramos algunos indicios de que la persistencia en la elección de ciertas opciones tecnológicas puede evidenciar un modo de vida, el cual probablemente fue similar en el período previo, durante e inmediatamente después del contacto con los españoles, por lo que consideramos que el cambio en la tecnología del inventario artefactual en Tarango podría ser una adecuación y persistencia del modo de vida y no necesariamente un cambio socioeconómico tajante como lo proponen las narraciones "terminales".

\section{A LA ORILLA DE TODO}

El crecimiento urbano ha limitado los proyectos arqueológicos convencionales, por lo que el salvamento arqueológico brinda la oportunidad de atacar nuevos problemas como el cambio tecnológico, la transformación cultural, la convivencia de distintas tecnologías, el estudio de la apropiación del paisaje, entre muchos otros. $\mathrm{Si}$ bien esto es una posibilidad, también significa un reto para el planteamiento de problemas y preguntas de investigación de largo alcance, previo a la intervención en el campo. De ahí la pertinencia del presente escrito, en donde se busca entender un fenómeno como el cambio tecnológico y el desarrollo histórico de un asentamiento pequeño como lo es Tarango.

La arqueología en el centro de México ha sido fuertemente marcada por la monumentalidad de sus hallazgos (Marquina, 1964; Piña Chan 1960; cfr. Vázquez León, 2003), mientras que la arqueología histórica ha centrado su interés en los edificios coloniales, ya sean civiles o religiosos (Fernández \& Gómez, 1998). De este modo, el estudio de poblaciones que no están ligadas directamente con grandes edificios ha recibido menos atención por parte de los especialistas. A esto habría que sumar que aun los trabajos que ponen interés en poblaciones más pequeñas, suelen estar asociados a tópicos particulares como los modos de vida, comercio, entre otros.

De esta manera, la arqueología en la gran urbe ha dado preferencia a los grandes sistemas de riego (Rojas, 1985), los grandes yacimientos de obsidiana (Pastrana, 1998), los grandes sistemas constructivos, por mencionar algunos ejemplos. Esto ha dejado de lado a las poblaciones marginales; es decir, a aquéllas que están en las orillas, tanto físicamente como en el imaginario académico. Debido a esta preferencia por lo monumental, se ha generado un vacío en la información. En muchos aspectos, el sitio Tarango está a la orilla 
de todo, al ser un pequeño asentamiento al Poniente de la Cuenca que no posee un inventario material que pueda considerarse "grande" en ninguno de los tópicos señalados. Tarango está incluso en la orilla geográfica de lo que fue la gran México-Tenochtitlán, y la falta de trabajos arqueológicos en la zona es muestra de esto. Del mismo modo, hasta hace unos pocos años la zona estaba a la orilla de la ciudad, social, política y urbanísticamente en cuanto a servicios.

La condición de marginalidad de la zona y la fuerte presión urbana que hay sobre ella ponen en riesgo permanente el patrimonio arqueológico que todavía se mantiene. Dar unos primeros pasos para tratar de entender el desarrollo histórico de este lugar es, al mismo tiempo, una vía para salvaguardar los vestigios materiales y su posible relación con las poblaciones cercanas. Por ello es clara la necesidad de ampliar las investigaciones en la zona, mantener una estricta vigilancia de las obras públicas y privadas que pongan en riesgo el patrimonio arqueológico, y contribuir a reconstruir la historia de la zona de Santa Fe.

\section{TECNOLOGÍA Y CULTURA MATERIAL}

El cambio cultural analizado a través de restos materiales, particularmente en el período del contacto entre europeos y americanos, ha sido un tema largamente trabajado en arqueología por distintos autores (Charlton y Fournier, 1993; Cusik, 1998; Lightfoot, 2005; Panich, 2013; Rogers, 1990; Stein, 2005). Aunque la mayoría de los trabajos son estadounidenses (Silliman, 2009; Greenfield, 1999), también México ha abordado este tema desde la arqueología, siendo los trabajos de Patricia Fournier especialmente importantes para entender estos procesos (Fournier, 1997; Charlton \& Fournier, 1993, 1997). Si bien el período del contacto ha sido abordado tradicionalmente por los historiadores (véase. León Portilla, 2008; López Austin, 1996), los trabajos de Fournier han mostrado cómo es que la arqueología y la historia pueden articularse en una sola investigación (Fournier, 1997). Mientras que Fournier se concentra en materiales como la cerámica, investigadores como Kennet Hirth y Andrews Bradford (2002) o Alejandro Pastrana (1998) lo hacen en la lítica.

Entendemos por tecnología “a los medios y actividades a través de los cuales las sociedades humanas hacen frente a su medio material y lo transforman" (Glick, 2000). En un sentido más amplio, es "un sistema de los comportamientos y técnicas guiados por las decisiones humanas" (Stark, 1998). Siguiendo este pensamiento, la "tecnología” no debe entenderse en singular, sino como una serie de "opciones tecnológicas" de las cuales se echa mano para resolver cierta situación (Stark, 1998); "las cosas siempre se hacen" en una tradición local (Wiessner, 1983:161), adoptando así cierta singularidad. Las alternativas seleccionadas por las personas, su elección de los materiales, los procesos productivos y la forma de sus productos reflejan una comprensión a fondo, interiorizada en la tradición de fabricación. Así, la tecnología se organiza en una serie de operaciones técnicas, que a su vez se articulan en cadenas operativas que requieren de la existencia de un conjunto de conocimientos (Lemonnier, 1986). Por lo tanto, la tecnología usada refleja elementos conscientes e inconscientes de opciones técnicas (Stark, 1998:6). Si quisiéramos ampliar la escala de observación, el conjunto de opciones técnicas podrían llevarnos más allá y suponer una opción en el estilo de vida.

Los estilos en los materiales arqueológicos suelen verse como un indicador de ciertas condiciones sociales que permanecen estables; por su parte, un cambio tecnológico suele asociarse a una transformación profunda en la sociedad que lo lleva a cabo (Stark, 1998). El cambio tecnológico puede definirse como "la fuente última 
de la mayoría de las innovaciones de artefactos y representa los cambios en el campo funcional, que se derivan en los factores del modo de vida, organización social y los cambios previos en el campo funcional" (Schiffer y Skibo, 1987:598). Los cambios de estilo en la cerámica, a su vez, "pueden ser ejemplos de avalanchas de eventos interconectados" (Bentley y Maschner, 2001), y a pesar de ello no implicar necesariamente una transformación en las estructuras sociales. Ahora bien, un cambio profundo de estilos en varios materiales concatenados sí nos pueden mostrar un cambio tecnológico, y éste a su vez puede estar asociado con un proceso de transformación de la sociedad como el que provocó la conquista en Mesoamérica.

Los cambios tecnológicos pueden responder a necesidades fundamentales o a necesidades adquiridas. En la primera acepción, las sociedades buscan resolver ciertas condiciones básicas que mejoran sus formas de vida; en la segunda, lo que se subsana es una necesidad creada por la misma sociedad, en cuyo caso la vida no depende de ello (Basalla, 2011). De esta manera, las necesidades adquiridas pueden responder más a lo que en arqueología conoceríamos como estilo, entendiéndolo en el sentido que Sackett (1977: 375) lo hace, como "el término que se emplea en referencia a la coherencia entre las opciones que se crean dentro de un contexto histórico determinado". La idea básica es que la explicación de cualquier cambio tecnológico debe basarse en una comparación rigurosa entre las alternativas (Schiffer y Skibo, 1987).

Ahora bien, si existe un cambio importante en la tecnología, podemos pensar que puede haber un cambio cultural. A simple vista podríamos asumir que, por ejemplo, la sustitución de herramientas de piedra por las de metal en una sociedad como la mesoamericana, significaría un cambio cultural profundo. Si bien puede ser así, en un examen histórico más detallado esto tendría sus matices, tal y como lo muestra Silliman para los indígenas norteamericanos, en donde la convivencia entre tecnologías originarias y europeas está registrada desde el contacto mismo y hasta por lo menos el siglo XVIII (Silliman, 2009). El cambio tecnológico y el uso de esa nueva tecnología no necesariamente comparten la misma dinámica que los cambios en los modos de subsistencia o la organización social, entre otros.

$\mathrm{Si}$, por ejemplo, el comportamiento tecnológico era una elección de los habitantes del sitio arqueológico de Tarango, éstos tenían una función que cumplir en el sistema social mayor, el tributario mexica. Si estos antiguos habitantes decidían vivir en el lugar y emplear un tipo de utillaje y técnicas para cumplir sus funciones de manera más confortable, lo que podríamos observar sería una primera manera de apropiarse del espacio con el uso de elecciones tecnológicas (como los sistemas de agricultura, el tipo de casas, el tipo de herramientas), y una serie de alternativas que se verían enriquecidas tras el proceso de conquista. Estas últimas podrían estar cumpliendo, de manera simultánea, funciones específicas dentro del sistema socioeconómico, como podrían ser la explotación de la madera, que en esta región permaneció con la llegada de los europeos. Como plantea Panich (2013), que se entremezclen tecnologías no sólo permitiría la resolución de necesidades, sino quizás también la persistencia de un modo de vida.

La perspectiva de la apropiación del espacio es parte del enfoque de la arqueología del paisaje (Anschuetz et al. 2001; Parcero-Oubiña, 2011; Tilley, 1994), en donde se asume que la ubicación de los asentamientos es una combinación de varios factores que desembocan en una elección racional con una percepción simbólica (Rapoport, 1969; Tilley, 1994:5). Además, es necesario reconocer la practicidad en el proceso de apropiación del espacio, atendiendo a los recursos disponibles, las opciones tecnológicas o incluso las comodidades, que no deben ser negados como factores importantes en la vida del ser humano (Thomas, 2001:17). De cualquier modo, "los lugares que se hacen ocupar adquieren, a través del tiempo, conjuntos particulares de significados 
y connotaciones que son al menos parcialmente interpretables desde la evidencia arqueológica y parecen ser demasiado importantes como para ser ignorados" (Tilley, 1994:8).

$\mathrm{Al}$ verlo de esta manera, entramos en una interacción entre el hombre y la naturaleza, puesto que "el ser humano transforma los espacios físicos en lugares significativos" (Anschuetz et al., 2001:159). Sin embargo, cabe señalar que esta significación también puede ser asignada a entornos naturales sin transformación antropogénica (Rapoport, 1979). El paisaje es un sistema de significación a través del cual se reproduce y se transforma la vida social, explorando procesos estructuralmente organizados. Asimismo, representa una forma de ordenamiento conceptual que hace hincapié en las relaciones (Tilley, 1994).

Varios autores (Anschuetz et al. 2001; Knapp \& Ashmore, 1999; Parcero-Oubiña, 2011; Thomas, 2001; Tilley, 1994) señalan que, al ser una construcción social, el paisaje involucra un contexto histórico-social específico; es decir, depende de cada lugar y momento, por lo que no existe un único paisaje, sino múltiples paisajes que se sobreponen y transforman. De esta manera, el paisaje "está en constante reformulación y reconstrucción, es estratigráfico como resultado de la superposición y destrucción de elementos preexistentes. Sin embargo, su génesis es resultado de la imposición del presente sobre todos los paisajes, en plural" (ParceroOubiña, 2011:15-17).

El paisaje en el que se centra este trabajo es el del final del posclásico tardío e inicios del mundo virreinal, dando cuenta de una continuidad de estructuras sociopolíticas como el altepetl -que, tomando el nombre de señorío, mantendrá en esencia las estructuras y condiciones previas a la conquista (Gibson, 1986). La gente de Tarango se apropió del paisaje de las cañadas al poniente de la cuenca mediante una serie de estrategias como terrazas, sistemas de riego, habitaciones, entre otras. Para ello usaron las opciones tecnológicas disponibles, transformando el medio en un lugar para vivir. Las elecciones en el uso del utillaje cerámico y lítico no sólo podrían haber sido una opción práctica (Tilley, 1994:8), sino también un elemento simbólico en la identidad de un grupo en el proceso de colonización (Véase Cusik, 1998:3; Panich, 2013; Stain, 2005:2). Por su parte, los cambios y las persistencias que se pueden observar en el material arqueológico podrían haber referido tanto a las estrategias de apropiación del entorno como a la resolución de necesidades fundamentales y adquiridas (Basalla, 2011). Por ello, es pertinente el uso de conceptos a diferente escala o multiescalares (Stain, 2005:6), como los de paisaje, tecnología y estilo. Estos conceptos permitirían evaluar si el cambio tecnológico realmente significó un cambio cultural en la forma de vida de los habitantes de Tarango.

\section{ABORDAJE ARQUEOLÓGICO DEL SITIO TARANGO}

Tarango fue originalmente reportado por el equipo de Williams Sanders en el proyecto de reconocimiento de superficie de la Cuenca de México en la década de 1970 (Sanders et al., 1979), siendo oficialmente registrado en la Dirección de Registro Público de Monumentos y Zonas Arqueológicos e Históricos. A través de la información bibliográfica, se le asignó una ubicación tentativa (muy probablemente por la mención de la barranca Tarango) y se le dio la clave E14A39-09-126. En la ficha de registro sólo se mencionó una estructura altamente destruida, una primera tarea era localizarla.

Los trabajos de construcción de la autopista se habían iniciado unas semanas antes de la llegada de los arqueólogos, removiendo grandes cantidades de sedimentos hacia la orilla de la vía (Figura 2). Allí se acumularon cientos de restos entremezclados de cerámica y lítica prehispánica, colonial y moderna. El 
predicamento en el que esta situación nos colocó fue que los posibles vestigios del sitio Tarango podrían haber sido destruidos o bien podrían haber quedado enterrados debajo de la tierra apilada a un lado del camino.

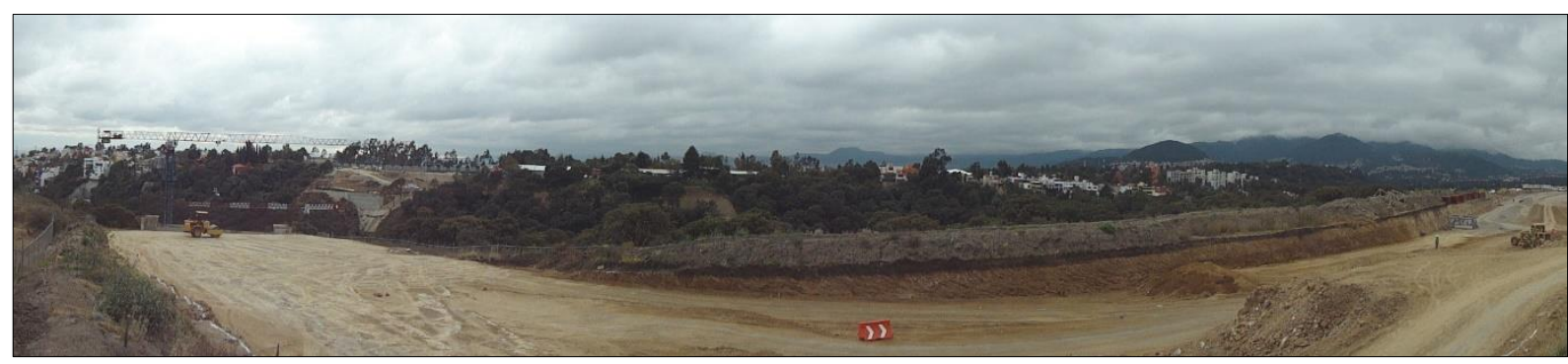

Figura 2: Panorámica general de la sección "Tarango" de la SVP. Fotografía de Mijaely Castañon.

En octubre del 2011 se realizaron trabajos de fotointerpretación en ortofotos de la década de $1970^{4}$. De esta manera, se logró localizar la zona principal de Tarango fuera del derecho de vía ${ }^{5}$ de la SVP, así como algunas anomalías en el paisaje. La fotointerpretación permitió detectar posibles vestigios a través de formaciones geométricas en intervalos constantes, los cuales fueron corroborados posteriormente en campo mediante un recorrido de superficie sistemático (Figura 3). La cantidad, tamaño y complejidad de las estructuras nos hicieron concluir que la zona principal de Tarango suponía un radio de unos 150m. Hacia el suroeste se localizaba la UE1EE1; y los vestigios se extendían a lo largo de una gran parte de la Loma de Tarango, llegando hasta las cañadas adyacentes (aunque en su mayoría se trataban de terrazas agrícolas y/o dispersiones de materiales) (Muñiz et al., 2013: 24-42).

Teniendo como referencia las anomalías, se realizó un recorrido de superficie, observándose que varias de ellas correspondían a terrazas. Posteriormente, se seleccionaron diversos espacios para hacer sondeos, y se buscó que hubiera muestras de los distintos elementos observados en superficie, tales como concentraciones de materiales, terrazas y unidades habitacionales (para más detalle, ver Muñiz et al., 2013). Se abrieron 15 unidades de excavación, con un total de $152 \mathrm{~m} 2$ de terreno excavado en tres frentes. El primero se localizó en el área más próxima a la concentración principal de estructuras (alteración 1, en la Figura 3), e implicó dos excavaciones extensivas correspondientes a dos unidades domésticas de $48 \mathrm{~m} 2$ y $44 \mathrm{~m} 2$ respectivamente, así como un pozo de sondeo de $4 \mathrm{~m} 2$. El segundo frente consistió en tres unidades de $4 \mathrm{~m} 2$ cada una; en todos los casos, asociadas a terrazas agrícolas. En el tercer frente se abrieron nueve unidades de $4 \mathrm{~m} 2$ y una de $12 \mathrm{~m} 2$, ubicándose un canal de riego (Muñiz et al., 2013).

\footnotetext{
${ }^{4}$ Los trabajos previos de documentación se llevaron a cabo en el Archivo Técnico de la Coordinación Nacional de Arqueología INAH, el archivo de la DSA-INAH. La fotointerpretación se realizó con el acervo de la mapoteca del Instituto de Investigaciones Antropológicas de la Universidad Nacional Autónoma de México, con el apoyo del Mtro. Gerardo Rodríguez, quien también nos apoyó en el diseño de las estrategias de prospección.

${ }^{5}$ El derecho de vía es "Franja de terreno que se requiere para la construcción, conservación, ampliación, protección y en general para el uso adecuado de una vía general de comunicación cuya anchura y dimensiones fija la Secretaría, la cual no podrá ser inferior a 20 metros a cada lado del eje del camino." (SCT 1997).
} 


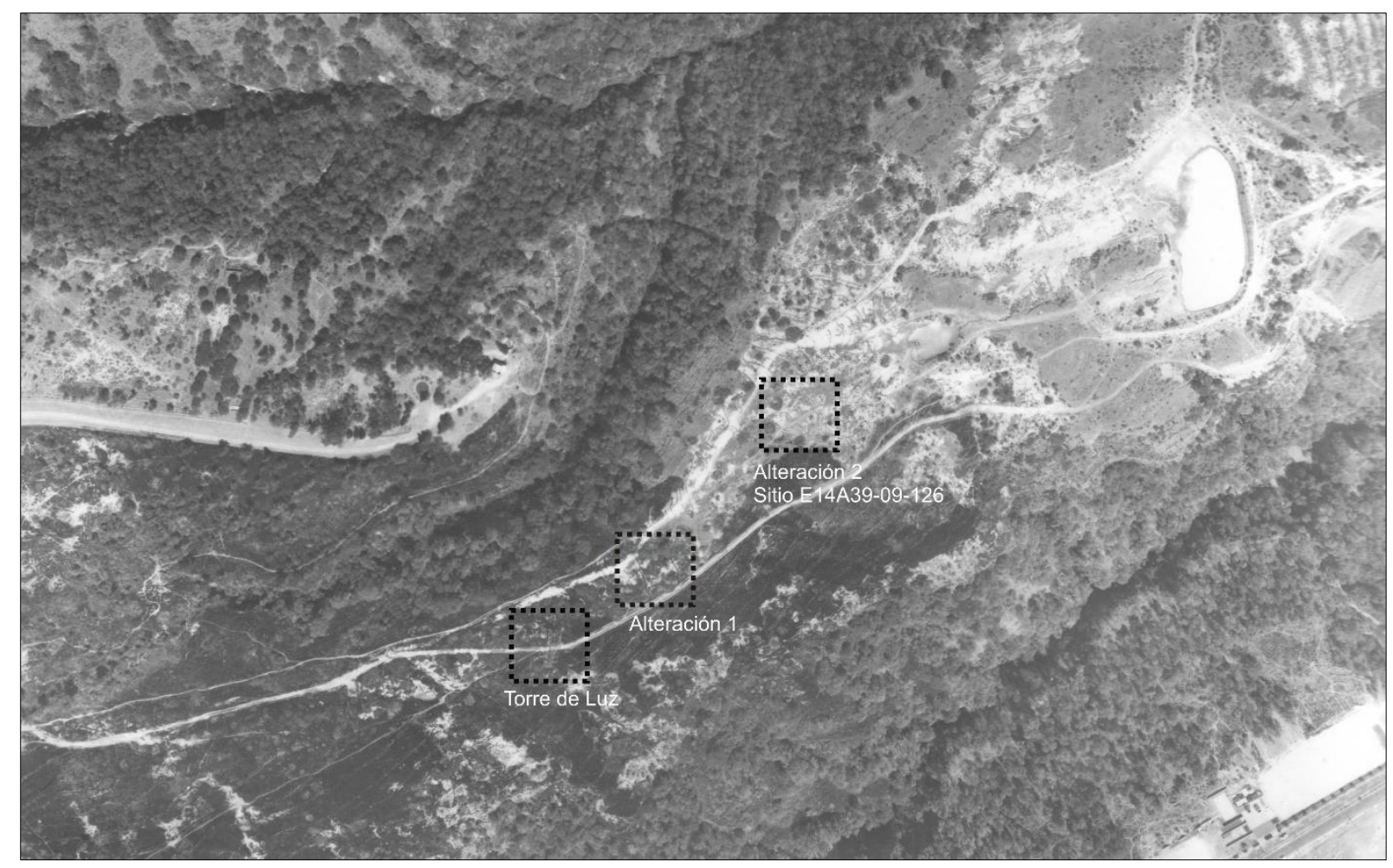

Figura 3: Ortofoto de la zona "Tarango" con posibles alteraciones arqueológicas. Cortesía de la mapoteca del instituto de investigaciones Antropológicas UNAM.

\section{EL CONTEXTO HISTÓRICO}

Hacia principios del siglo XVI, se calcula que la población de la Cuenca de México fue de entre uno y tres millones de habitantes, implicando el mayor auge poblacional en la historia de la región (Gibson, 1986:7-8). La presencia y el control hegemónico del gobierno mexica fue clave en este proceso (Paredes, 1986:241-242). Para satisfacer el cada vez más alto consumo de productos, los mexicas desarrollaron un sistema económico muy sofisticado (Carrasco, 1971), en el cual se articularon zonas de agricultura intensiva, como Xochimilco (Rojas, 1985), y lugares que proveían productos especializados como la lapidaria, metalurgia y artefactos de concha, entre muchos más (Velázquez, 2007). La organización político-administrativa en el período de la Triple Alianza fue a través de una división en altepetl (unidad político administrativa prehispánica), a su vez subdivididos en calpulli o barrios (Calpuleque en plural) (Gibson, 1986).

Coyoacán fue conquistado hacia el año de 1430 por la Triple Alianza encabezada por los mexicas. Desde entonces y hasta la conquista española, fue parte del sistema tributario mexica, siendo sujeto de las presiones económicas, políticas y sociales del floreciente imperio. Coyoacán fue regido por los Tecpanecas, quienes tenían el control del sur-poniente de la Cuenca de México, así como de Tacubaya y Azcapotzalco (Horn, 1992). Tacubaya parece haber sido un Altepetl independiente de Coyoacán pocos años antes de la conquista; sin embargo, en el período colonial fue reclamado como parte del marquesado del Valle de Oaxaca, propiedad de Hernán Cortés, quedando en una especie de condición político administrativa dual con Coyoacán (Horn, 1992). 
Tarango se ubica sobre una de las cañadas que bajan hacia la Cuenca de México, muy cerca de los márgenes exteriores del viejo Altepetl de Tacubaya, en la actual zona conurbana de Santa Fe. Esta cañada corre desde el poniente hacia la cuenca por una planicie alargada, delimitada por dos grandes barrancas (Mixcoac y Tarango), hasta llegar a su salida natural a la altura del antiguo asentamiento de Mixcoac. En las inmediaciones de esta zona Gibson (1986) consigna la presencia de un poblado llamado Acaxóchitl o Acasúchil, el cual fue desagregado de Tacubaya para fundar allí el hospital de Santa Fe en 1532 (Gibson, 1986: 102). En el Archivo General de la Nación no se localizaron más nombres de poblaciones asociadas al área de estudio previo a la instalación del hospital de Santa Fe a finales del siglo XVI (AGN gd58 Indios. 1583. Vol. 2, exp. 629, 633 y 634); Acasuchitl es mencionado por Gibson (1986: 101) y Pineda (2000: 51); mientras Horn (1992: 40) los relaciona con la presencia tecpaneca, Pineda lo coloca como el antecedente directo de Santa Fe.

La llegada del mundo occidental y la dominación española sobre el México central mantuvo en cierta medida una parte de la organización sociopolítica, ya que a nivel regional las distintas formas administrativas novohispanas se superpusieron al antiguo Altepetl. Esto permitió que el funcionamiento interno de la sociedad indígena provincial conservara parte de sus rasgos anteriores a la conquista (Gibson, 1986). Los estragos poblacionales tan característicos de este período, así como la ambición de los conquistadores habrían obligado a modificar paulatinamente este modelo, aunque nunca llegaría a perderse totalmente. El período de transición entre la sociedad prehispánica y su Altepetl, y la sociedad plenamente virreinal ha sido poco estudiado a nivel arqueológico y es el tipo de contexto al que nos enfrentamos en el PSAVP.

\section{EL CONTEXTO ARQUEOLÓGICO}

Sobre un pequeño recodo de tierra cercana al Parque Tarango se localizaron dos unidades habitacionales. Una de ellas fue denominada UE1EE1, siendo excavada mediante niveles métricos y capas estratigráficas. La estructura mide $12 \mathrm{x} 4 \mathrm{~m}$. y es parte de un complejo habitacional que continuaba hacia el sur y el oriente. La misma fue edificada con rocas grandes consolidadas entre sí con cementante de lodo y tierra arcillosa, piedras más pequeñas y material cerámico (Figura 4).

La estratigrafía de la UE1EE1 fue muy similar a la del resto de las excavaciones. La capa B presentó textura arenosa y correspondió a un relleno post-ocupacional. La capa C-D (a 1 metro de profundidad aproximadamente) fue de tierra areno-arcillosa. Allí se localizaron la mayoría de los materiales arqueológicos de dicha excavación, incluyendo tiestos prehispánicos, transicionales, coloniales tempranos y un clavo colonial. Se trató de un piso de ocupación muy uniforme con unos $20 \mathrm{~cm}$. de espesor. Este nivel terminó con el inicio de un muro y la capa E, la cual comprendió un relleno para acondicionamiento del piso. Ambos elementos fueron soportados por un afloramiento de roca volcánica en proceso de degradación, conocido como "tepetate". Es importante destacar que el piso (capa C-D) no mostró diferencias en su composición, tales como lentículas horizontales o interfaces, que nos hicieran suponer una interrupción en la ocupación, y que los materiales encontrados estuvieron entremezclados. 


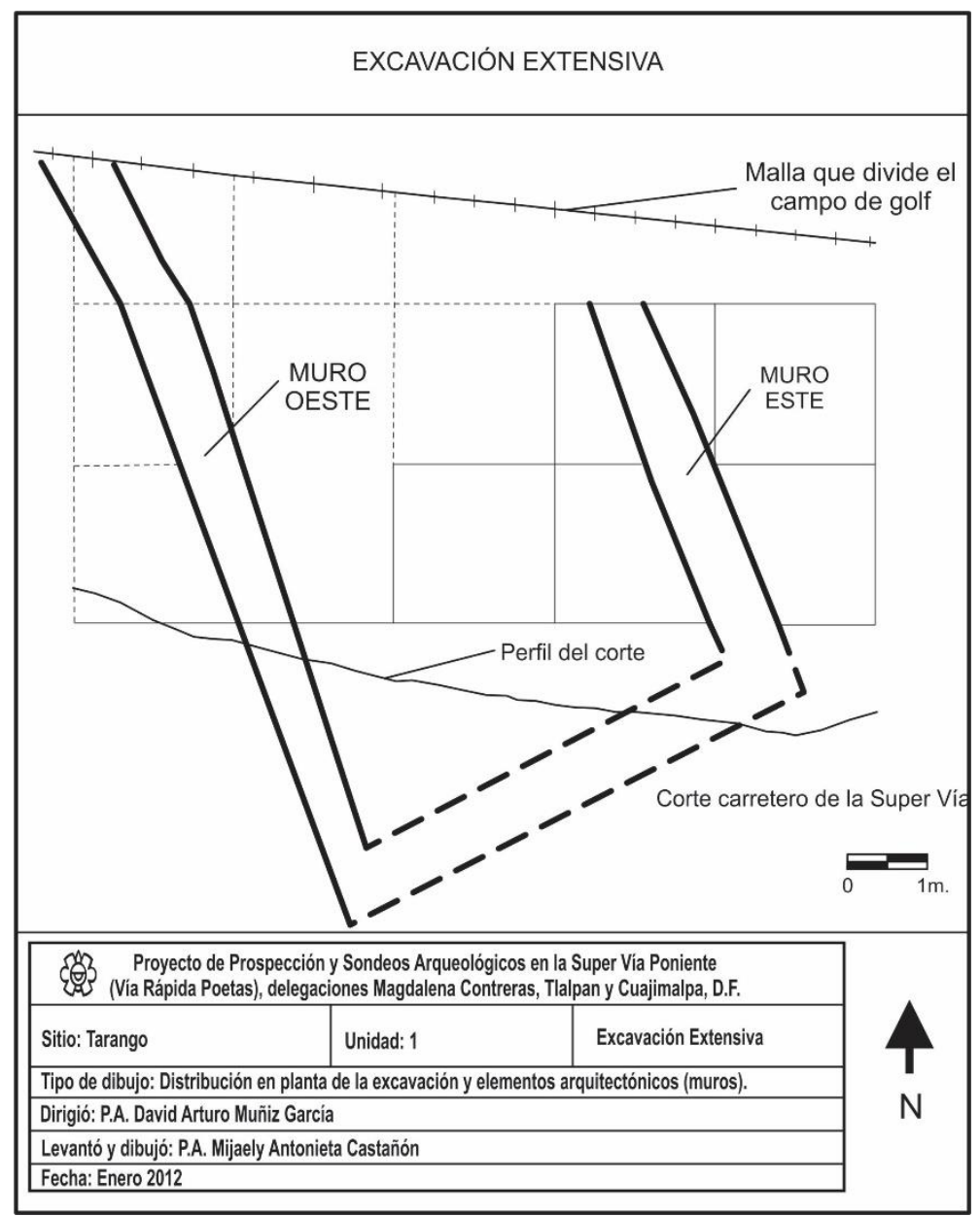

Figura 4: Dibujo de planta y de perfil de la ue1ee1. Elaboró Fernando Orduña.

En la capa E se localizaron dos fogones, ambos cercanos al muro en sus lados este y oeste respectivamente. El fogón ubicado al este se denominó fogón 1 y se localizó a unos $1.60 \mathrm{~m}$. de la superficie. En su interior se identificaron restos de materiales líticos y cerámicos, incluyendo la base de dos cajetes trípodes rojo sobre bayo y un fragmento muy grande de cajete transicional anaranjado alisado (posiblemente, alguna especie de ofrenda de construcción). El fogón 1 presentó un diámetro de cerca de $1.08 \mathrm{~m}$., con paredes delimitadas por la consistencia sumamente compactada de tierra (quizás, termo-alterada intencionalmente). Fue excavado en su totalidad, registrando una profundidad máxima de $31 \mathrm{~cm}$. En su interior se localizaron una gran cantidad de trozos de carbón, 13 fragmentos de hueso de vaca, una navajilla de obsidiana y tiestos tardíos aztecas, transicionales y coloniales tempranos. En el interior del fogón, la compactación de la tierra fue baja y el sedimento resultó homogéneo. Allí se encontraron tiestos revueltos de distintas temporalidades, cuatro de los cuales presentaron huellas de termo-alteración posterior a su deposición (Figura 5). Pensamos que el fogón fue usado de manera continua desde el momento mismo de la ocupación de la estructura (por los materiales más tempranos, hacia $1428 \mathrm{dc}$.) hasta su abandono cerca de finales del siglo XVI.

La proporción de cerámica localizada en el fogón 1 puede ser reveladora de la intensidad de su uso por períodos: el tipo cerámico con mayor presencia fue la loza colonial temprana, con 23 tiestos, ubicada temporalmente entre 1551 y 1600 (Fournier et al. 2009); el segundo tipo en proporción fue el Azteca Alisado, con 12 fragmentos el cual data entre1428 y 1521 (Vega Sosa, 1975); el tercer tipo más recurrente fue el 
transicional, con 10 piezas, que tiene un espectro temporal de 1521 a 1551. Cabe destacar que hubo además tipos cerámicos prehispánicos como el Azteca I, II III, con seis fragmentos en total, y varios más coloniales (Ciudad de México verde sobre crema, vidriados monocromos).

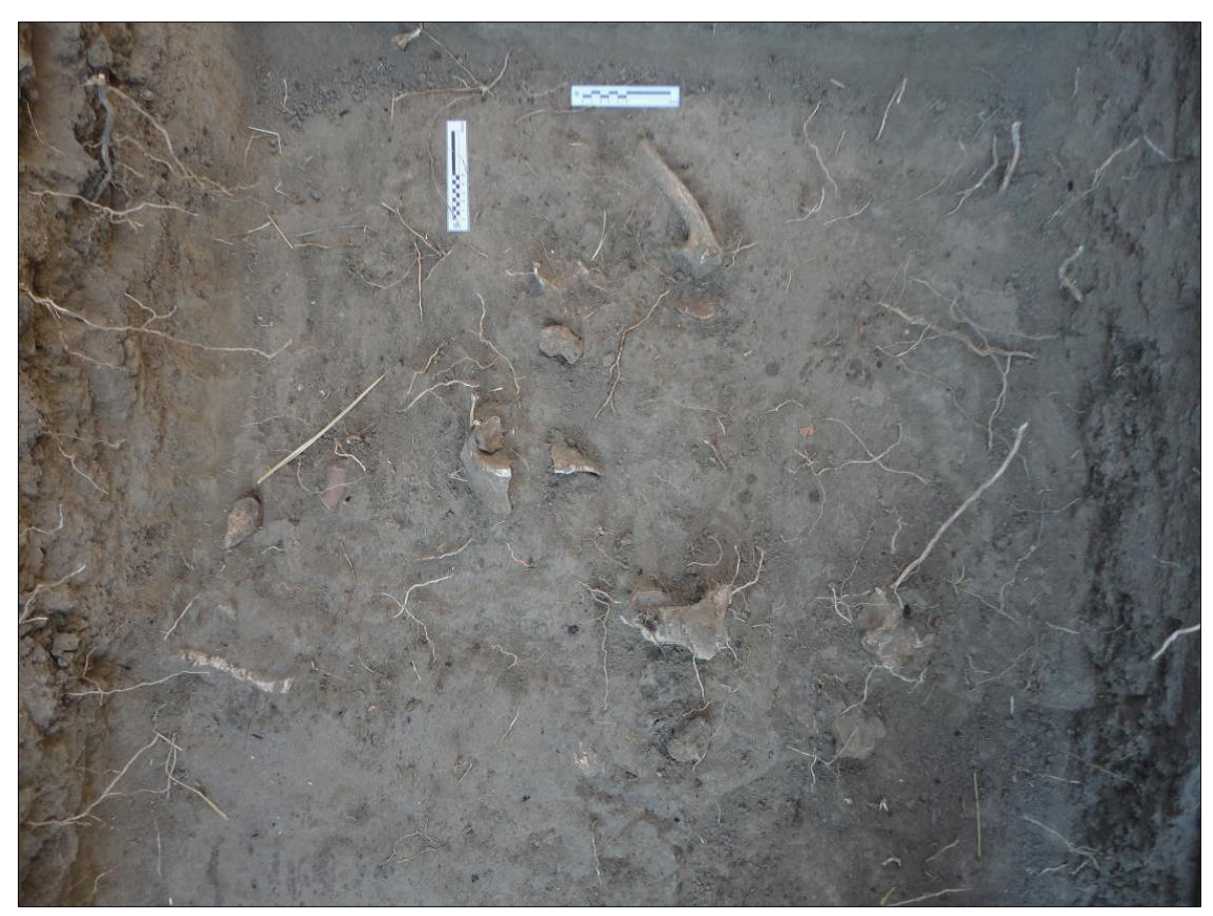

Figura 5: Huesos de vaca en el interior del fogón 1 de la uel ee1. Fotografía Mijaely Castañon.

\section{RESULTADOS}

En un trabajo previo se presentaron y discutieron algunos otros resultados que permiten completar la panorámica de los hallazgos en Tarango por parte del PSASVP. Algunos de los aspectos más importantes de ese trabajo fueron: 1) la localización de dos unidades habitacionales en la poligonal de la obra, cuyas características parecieron corresponder a una ocupación no permanente o por lo menos de manufactura burda, además de más de una docena otras unidades habitacionales en la Loma de Tarango; 2) El hallazgo de evidencias de un sistema de riego mediante zanjas excavadas en el tepetate, múltiples terrazas agrícolas con dos tipos predominantes de sistemas constructivos, presencia principal de monocultivos, y una ubicación que permitía la acumulación de sedimentos y su distribución dispersa en las distintas cañadas y pendientes aledañas; 3) El reconocimiento de la presencia de concentraciones de lítica y cerámica (Muñiz y Sumano, 2017).

El entorno construido conforma la huella más visible de la apropiación del paisaje (Parcero-Oubiña, 2011); en este caso, terrazas y habitaciones que permanecieron inalteradas a lo largo de la ocupación de Tarango. Por otro lado, en la vida cotidiana fue notorio el impacto de la conquista a través de materiales y animales desconocidos previamente, como el vidrio, el hierro y el ganado vacuno, todos presentes en la excavación. Estamos ante una combinación de cambios y persistencias en diferentes escalas; sin embargo, al ver un poco más en detalle notamos que la tecnología cambió, aunque no necesariamente sus estilos y funciones. En este sentido, el trabajo arqueológico en Tarango parece indicar que las condiciones de vida fueron similares durante el tiempo que se ocupó el lugar. 
La cerámica es posiblemente el material más recurrente en los contextos arqueológicos de México; por tanto, es uno de los más trabajados por los investigadores. A partir de la cerámica se ha desarrollado gran parte de las tipologías que tienen una correspondencia cultural (Wajari, 2010), y a partir de los estilos observados se han inferido, en buena medida, los procesos sociales en Mesoamérica.

La tecnología prehispánica de producción cerámica consistía en la extracción de materias primas, molienda, amasado, formación de objetos, acabado de superficie, secado y cocimiento (Canto, 1986). Por su parte, la tecnología novohispana de cerámica introdujo hornos que permitían alcanzar una mayor temperatura y obtener cerámicas delgadas y resistentes. Entre otras cosas, produjo lozas vidriadas, siendo especialmente apreciadas las de tipo mayólica (Fournier et al., 2009). En el proceso de adaptación entre una tecnología cerámica y otra, hubo un período de unos 30 años, de 1521 a 1551 (tomando en cuenta la fecha de las primeras mayólicas) (Fournier et al., 2009), donde se produjo una cerámica muy característica por el color rosado de su pasta y que se ha denominado transicional (Fournier y Charlton, 1996; Figura 6). En el PSASVP se localizaron tiestos con estas tres tecnologías: la prehispánica, la transicional y la colonial. La prehispánica correspondió al período Posclásico tardío en sus fases azteca (1428-1521); la transicional implicó los años de 1521 a 1551; y la colonial, los siglos XVI al XVIII (Figura 6).

La tipología cerámica tuvo en cuenta los criterios recopilados por Cervantes et al. (2007) para el periodo Posclásico en la Cuenca de México, y los de Charlton et al. (2007) para el periodo Colonial temprano, considerando también los textos de Vega Sosa (1975), y Fournier y Blackman (2007). Se realizó la descripción de la forma de la pieza, clasificando sus partes en cuerpo, borde, fondo, base, soporte y asa, así como la función general. Se analizaron un total de 1365 tiestos. De ellos, 688 (el 34\%) se recuperaron en las unidades habitacionales (la gran mayoría, en el piso de ocupación). De esta cerámica el 21\% consistió en fragmentos monocromos que no fue posible asociar a ningún tipo. Los otros 546 tiestos se repartieron de la siguiente manera: 221 (49\%) prehispánicos, 58 transicionales (11\%) y 267 coloniales (40\%) (Figura 7).

Basándonos en Charlton et al. (2007), los complejos cerámicos del período transicional y colonial temprano presentes en la Cuenca de México constituyeron una continuidad en el empleo de la loza anaranjada (1428-1521) de la tradición cerámica Azteca, pero con algunos cambios en cuanto a la calidad. Dentro de este complejo estuvieron presentes la loza anaranjada-tipo anaranjado monocromo, la loza Tlatelolco (loza tipo adicional), la loza transicional bruñida, la loza transicional anaranjado monocromo, la loza transicional anaranjado inciso, la loza transicional rojo monocromo, la loza anaranjado-tipo negro sobre anaranjado y la loza roja colonial. También se identificaron tipos a los que Charlton et al. (2007) denominan lozas de intercambio, lozas de usos específicos, y las mayólicas como el Ciudad de México verde sobre crema y el San Luis azul sobre blanco (Figura 6). 

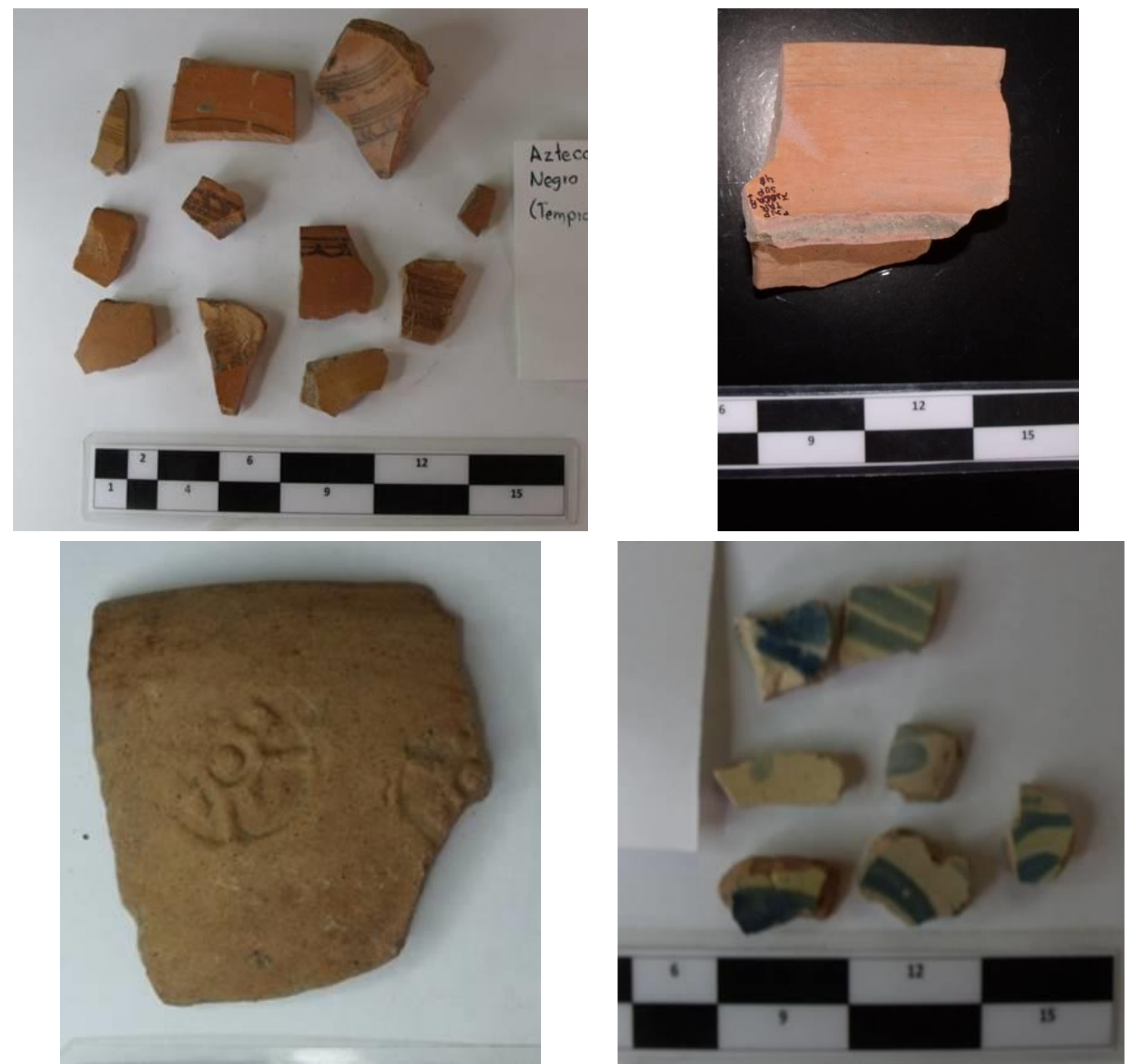

Figura 6: Cerámica asociadas a la ue1 ee1: Posclásico Tardío Azteca III (1), Cerámica transicional (2), Cerámica transicional decorado con sello (3), colonial temprana Ciudad de México azul/crema (4).

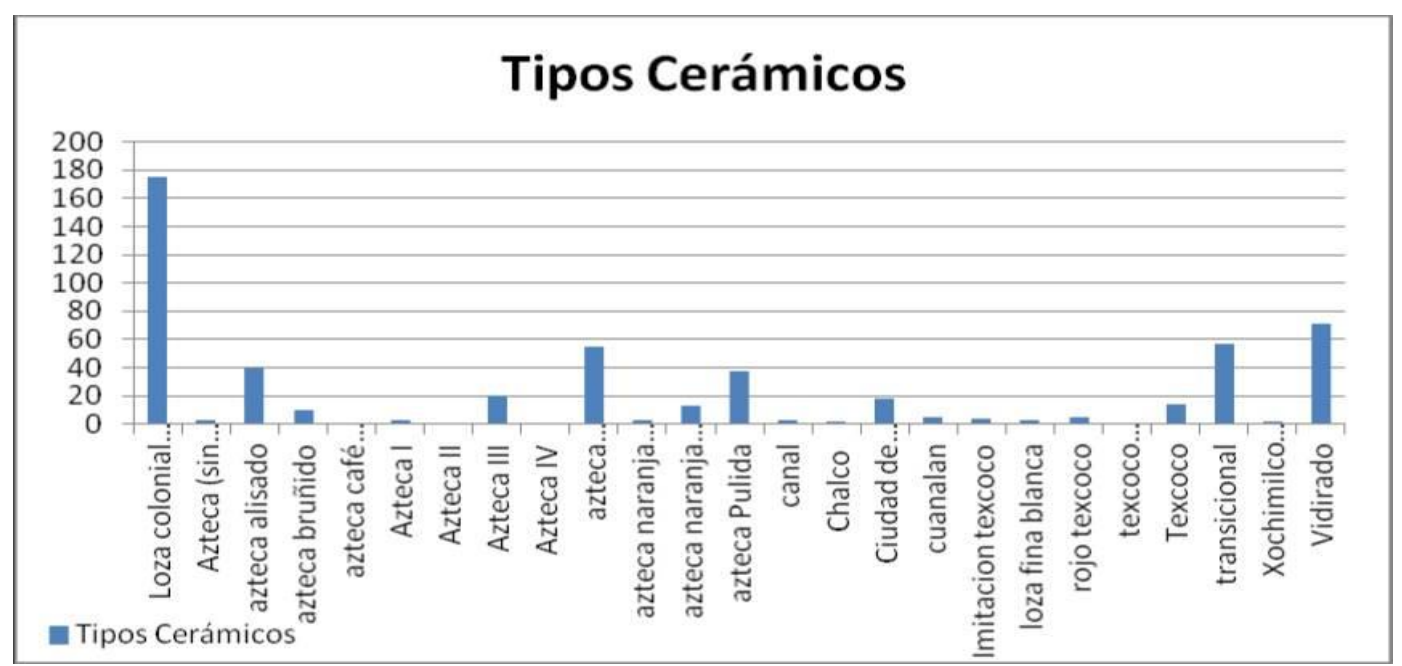

Figura 7: Tabla con los tipos cerámicos presentes en la excavación. 
LÍTICA

Los artefactos líticos tienden a ser considerados emblemáticos de la cultura material de los nativos americanos y de su identidad en el período colonial. La continuidad de estos suele ser consideradas como parte de una persistencia e identidad, mientras que su ausencia es vista como un signo de cambio cultural(Cobb, 2003; Silliman, 2009:223, Panich, 2013). En el México antiguo se tenía un amplio manejo de distintos tipos de piedras como el pedernal o la toba; sin embargo, la obsidiana fue una materia prima esencial en el desarrollo de las sociedades del Altiplano Central, pues se empleó en actividades productivas, militares, rituales y suntuarias. También se distribuyó como material de intercambio a nivel local, regional y a larga distancia, desde el Preclásico hasta la conquista europea. Los instrumentos de trabajo de obsidiana se situaron en la base de diversos procesos productivos: domésticos, agrícolas y artesanales (Pastrana, 1998:21). Por lo tanto, la obsidiana "mantiene gran potencial para la interpretación de los procesos culturales en la prehistoria Mesoamericana” (Hirth y Bradford, 2002).

En el PSASVP se localizaron 48 objetos líticos, aunque destacaron dos hallazgos asociados a la unidad habitacional UE1EE1. El primero fue una semi-esfera de basalto con retoques en la parte distal, que pareció ser un desfibrador. El segundo correspondió a un par de navajillas prismáticas en el interior del fogón, asociadas a huesos de vaca. Ambas navajillas presentaron un gris veteado, característico de la mina de Otumba (Gazziola, 2009. La primera midió 2.64 x $1.34 \mathrm{~cm}$; y la segunda, $3.02 \times 1.5 \mathrm{~cm}$.

Las navajillas serán un elemento central en nuestra discusión acerca de la continuidad y el cambio cultural, pues si bien es necesario hacer pruebas arqueométricas para saber si fueron usadas sobre los huesos ${ }^{6}$ encontrados en el fogón de Tarango, sí podemos asumir una convivencia entre la tecnología lítica y los productos venidos de Europa. Uno de los principales usos de la obsidiana fue el de cortar, aunque la materia prima tuvo una gran connotación simbólica. La llegada de la tecnología europea de los metales provocó un paulatino abandono de la obsidiana; en este caso, el cambio tecnológico resultó evidente en el registro arqueológico.

En las unidades habitacionales de Tarango se encontraron evidencias del uso continuo de cerámica y obsidiana, principalmente utilitarios, desde el posclásico y durante el período colonial. También se identificaron un par de fogones de gran tamaño con estos materiales revueltos con hierro y huesos de vaca. De este modo, no sólo tenemos la presencia de un cambio tecnológico que pudo ser útil en la resolución de las necesidades de los habitantes, sino también la persistencia de cierto estilo. Fournier y Charlton (1996:72) mencionan que "Posterior al contacto inicial y a la difusión de elementos de cultura material de origen europeo, hay evidencias de un florecimiento de la tradición cerámica derivada de la precortesiana, este nuevo desarrollo representa una retención inicial de algunos aspectos de identidad cultural indígena con un estímulo marcado de la cultura española”. En Tarango, en una escala muy acotada, podemos observar una condición similar a la señalada por Fournier y Charlton; es decir, la adopción de nuevas tecnologías para resolver distintas necesidades, que se reflejan en un cambio en el inventario artefactual, pero al mismo tiempo una persistencia en la forma de vida.

\footnotetext{
${ }^{6} \mathrm{Si}$ bien en los huesos también representan una posible línea argumentativa, en cuanto a la diferencia de marcas de corte realizadas con instrumentos de piedra o de metal y el patrón de trozamiento de los huesos, este análisis no pudo ser llevado a cabo, siendo una línea de trabajo pendiente.
} 


\section{DISCUSIÓN}

El período del contacto entre europeos y americanos en el siglo XVI nos permite poner a prueba las ideas que se tienen en arqueología acerca del cambio cultural en relación con la innovación tecnológica. De manera particular para la Cuenca de México, tenemos el apoyo de fuentes históricas que nos permiten alcanzar una comprensión más amplia de este fenómeno. Excepto la tecnología, los elementos arqueológicos analizados fueron similares durante el posclásico tardío y los primeros años del período colonial. Así pues, el cambio tecnológico pareció conformar una adición a otras opciones tecnológicas que permitieron la resolución de necesidades de una manera más práctica. Desde este marco, podemos entender contextos como el de Tarango, donde hay materiales entremezclados.

En el caso de las exploraciones arqueológicas en el marco del PSASVP, se consideraron dos elementos de análisis: la cerámica y la lítica. En Tarango, la llegada de la tecnología europea tuvo un impacto notable en la variabilidad del registro arqueológico. Si bien esto necesita ser corroborado con más ejemplos en contextos similares, el salvamento arqueológico de Tarango ofrece una posible referencia a la discusión. En el caso de la cerámica, el uso de hornos y técnicas de acabado permitieron la fabricación de lozas vidriadas; en particular, las llamadas mayólicas, asociadas a las tradiciones hispánicas de manufactura (Fournier et al., 2009).

Los tipos cerámicos españoles desplazaron rápidamente a las tradicionales cerámicas bruñidas del período prehispánico. Aunque la cerámica se mantuvo como uno de los artefactos más usados por la población de la Nueva España, su forma, decoración y estilo se modificaron sensiblemente (Fournier et al., 2009). Esto nos muestra que el cambio cultural se produjo en ciertos aspectos del inventario artefactual de la sociedad. Si bien la función y el uso fueron similares, su forma y decoración cambió, permitiendo una forma de resistencia cultural a través de la persistencia, tal y como lo muestran algunos ejemplos planteados por Lightfoot (2005), Silliman (2009) o Panich (2013). En este sentido, Panich (2013:116) menciona que: "las varias disyunciones entre la tecnología y la organización social que se revelan en la investigación arqueológica son, en muchos casos, reflejadas especularmente por continuidades importantes en la práctica y la identidad que demuestran una trayectoria dinámica aunque trazable desde los tiempos pre-contacto hasta el fin del período colonial y más allá”. Lo anterior puede ser asociado a una continuidad en elementos fundamentales de la vida diaria, las relaciones, las actividades productivas y las formas de subsistencia que se mantuvieron casi inalterados a lo largo del período virreinal. Esta aseveración es apoyada por la información proveniente de fuentes históricas (Escalante, 2010; Fournier, 1997; Fournier et al., 2007; Gibson, 1986; Sahagún, 2010).

La lítica también fue sustituida rápidamente por la aparición del metal; sin embargo, al igual que en el caso de la cerámica, también existió un espacio temporal de convivencia entre ambas tecnologías. De acuerdo con algunos autores (Cusik, 1998; Greenfield, 1999; Silliman, 2009; Panich, 2013), el uso de nuevas tecnologías parecería complicar la identificación de identidades, debido a que nuevos artefactos desplazan a los antiguos de manera acelerada y generalizada, convirtiéndose en “opciones tecnológicas” (Stark, 1998). En muchos casos, como el de los habitantes de Tarango, la población prefiere el uso de nuevas tecnologías para resolver su vida cotidiana, generando un nuevo inventario artefactual. Si bien hay que ponderar la obligatoriedad o restricción en el uso ciertos materiales, su localización en zonas marginales como Tarango podría indicar el empleo generalizado del metal y la cerámica vidriada por parte de la población común. Entonces, durante el período del contacto, las personas podrían decidir usar una innovación tecnológica no 
como forma de resolver una "necesidad fundamental" (Stark, 1998), sino como una decisión propia, con los matices y consecuencias que esto puede tener. Panich (2013: 114) menciona que: "Los artefactos líticos también ofrecen una mirada importante en las formas en que los nativos californianos creativamente emplearon tradiciones culturales duraderas en el período colonial. Los líticos son comúnmente encontrados en las misiones y sitios contemporáneos en California, aunque muchos marcos explicatvos asumen que la tecnología en piedra era inferior a los implementos de metal traídos por los españoles. Aquí, una aproximación basada en la práctica puede permitir a los arqueólogos considerar el contexto de cómo estos arttículos estabann siendo usados y las relaciones sociales que representaban".

De esta manera, un cambio cultural se vuelve una cuestión de opciones tecnológicas y persistencias culturales. Si bien la nueva tecnología es consecuencia de una imposición violenta como la conquista, también puede representar una decisión. Hay ejemplos en otras regiones y en otros aspectos de la vida sobre la "resistencia" cultural de los grupos dominados (Monteiro, 2008; Panich, 2013; Silliman, 2009; Scaramelli, 2005). Es importante cuestionarnos qué innovaciones resultan bien recibidas, cuáles son rechazadas, y ponderar el contexto histórico cultural para poder afirmar con mayor contundencia el proceso de apropiación y persistencia cultural en grupos colonizados. Al hacerlo, podremos alejaremos un poco de los planteamientos dicotómicos acerca del proceso de formación de las sociedades mestizas en América, que nos han llevado a la generación de narraciones "terminales" que suelen englobar estos procesos en generalidades no siempre certeras.

Una narración "terminal" que es común encontrar en los textos generales de historia es que el proceso de conquista y posterior implantación de la colonia en América implicó un cambio significativo en ciertas estructuras (Pérez Tagle et al., 2014; Rodríguez et al., 2014). Si bien esta idea ha comenzado a moderarse, reconociendo la persistencia del mundo indígena, aún no resulta claro cómo ha sido este proceso. En uno de los textos de mayor difusión en México, Luis Gonzáles dice "La conquista de México significó la desaparición de los antiguos señoríos prehispánicos, pero de ningún modo la destrucción total de la antigua civilización mesoamericana" (González y Gonzalez, 2009:17). En ese sentido, ejemplos de la vida cotidiana, como el de pequeñas poblaciones en los márgenes de México-Tenochtitlán, pueden aportar elementos de análisis en la discusión. Si consideramos la idea de evaluación multiescalar, tomar en consideración el tamaño y ubicación de un lugar como Tarango tampoco es cosa menor. Por ejemplo, Fournier y Charlton (1996:79) mencionan que: "Los indígenas de las áreas rurales, así como de las clases bajas fueron menos afectados y en épocas posteriores que quienes radicaban en las urbes y los miembros de la élite autóctona.”

De manera paralela, la idea de que la introducción de la tecnología europea en el inventario artefactual mesoamericano implica un cambio cultural, puede ser vista como una categoría rígida que no contempla ni matices ni períodos transicionales (Stark, 1998). Ello complica el estudio de etapas como el posclásico tardío y el consecuente paso a la época virreinal. Por supuesto que un ejemplo de caso no modifica por sí mismo una narración arqueológica, pero sí puede ayudar a contextualizarla histórica y culturalmente. También es necesario evaluar la influencia de variables sociales como las diferencias de poder, el género, el sexo, la clase social, la edad, el origen étnico, y ponderar las características reales del rendimiento de los artefactos (Schiffer et al, 2001). 


\section{CONCLUSIONES}

El crecimiento de la Ciudad de México representa un serio obstáculo en el desarrollo de proyectos arqueológicos. Ante esto, el salvamento arqueológico es una alternativa para la resolución de preguntas de investigación. El presente trabajo tiene algunas de sus principales limitaciones en el tamaño de la muestra y la representatividad de los datos para interpretar fenómenos como el cambio y la persistencia. Sin embargo, ante el desbordamiento de una urbe como Ciudad de México, el salvamento arqueológico aporta información que puede ser usada y discutida en el marco de problemáticas de mayor escala. Estudiar el cambio y la persistencia cultural desde las transformaciones arqueológicas en el inventario artefactual requiere una variabilidad de muestras que hoy en día es muy difícil recopilar con un proyecto arqueológico convencional, pero que es plausible congregar y discutir a partir de la información de múltiples salvamentos. Como éste, hay muchos derroteros planteados, y otros más por hacer, donde el salvamento puede sumar información e interpretaciones para continuar con la construcción constante del conocimiento arqueológico.

Los datos generados en el PSASVP nos llevan a pensar que las opciones tecnológicas usadas por los habitantes de Tarango son parte de la resolución de sus necesidades fundamentales y adquiridas. A través de la elección de sus opciones tecnológicas debieron poder cumplir con una función en el sistema económico mexica y luego adaptándolo al mundo novohispano. De este modo podemos entender cómo es que los habitantes de Tarango/Acaxochitl podrían haber estado viviendo en un entorno difícil, así ellos se adaptaban y moldeaban tanto al entorno como a las diferentes condiciones socioeconómicas. A través de la UE1EE de Tarango observamos tres momentos de toma de decisiones: 1) la última parte del período posclásico (cerámica azteca I, II y III, y lítica); 2) el período de transición o de contacto entre el mundo español y el indígena (azteca transicional, colonial pasta rosa); y 3) los primeros 30 o 40 años del período virreinal (mayólica temprana, lítica y hierro). Lo que parecería ser tres rupturas o momentos distintos parecen ser más bien un continuó, tal y como vemos en la estratigrafía, los estilos y la funcionalidad de los materiales, es muy probable que esto fuera parte de un proceso de persistencia.

Consideramos que en Tarango el proceso de ocupación pudo iniciarse con la presión demográfica de México-Tenochtitlán y su necesidad de recursos. Sus habitantes se apropiaron del entorno y generaron un modo de vida que se mantuvo constante. De acuerdo con las fuentes, es probable que esto cambiara cuando las personas fueron congregadas en el convento de Santa Fe, lugar en que sería valioso conocer si las elecciones tecnológicas se mantuvieron o cambiaron. Desde hace unos 30 años, la zona poniente de la cuenca ha experimentado un nuevo proceso de ocupación que ha llevado, entre otras cosas, a la construcción de vialidades como la Súper Vía Poniente que motivó la realización del PSASVP. Los procesos de cambios y persistencias entre el momento del abandono de Tarango y su recuperación arqueológica son otra vía más de investigación que debe ser explorada si deseamos evaluar el cambio tecnológico en términos más holísticos; es decir, como un proceso lento, complejo y de vaivenes que permite ligar nuestro pasado con nuestro presente.

Hoy en día sigue habiendo gente que transita por el poniente de la Cuenca, en ondas migratorias discontinuas, y tan efímeras como un solo día. Estos nuevos actores sociales, al igual que los antiguos, toman opciones tecnológicas en función de sus condiciones socioeconómicas y culturales, y de la misma manera modifican dinámicamente el registro material de sus actividades. Los habitantes recientes de Santa Fe también participan de una relación económica dependiente de la parte baja de la Cuenca. Tal vez los arqueólogos del 
futuro interpretarán estas nuevas huellas en el poniente de la Cuenca en función de un gran cambio cultural. No podemos saber si esta hipotética evaluación corresponda con la percepción de los actores de estos procesos, de la misma manera que hoy no podemos estar completamente seguros de que la interpretación aquí esbozada y otras distintas por venir, se acerquen a la percepción de los antiguos pobladores de Tarango.

\section{AGRADECIMIENTOS}

A la Dra. Blanca Maldonado, al Dr. Rodrigo Esparza y a la Dra. Magdalena García del CEQ-COLMICH por sus comentarios hacia el trabajo en el marco de sus respectivos cursos. A la Arqlga. Gabriela Mejía Appel de la DSA-INAH por sus valiosos comentarios y correcciones a este texto. A la Arqlga. Susana Lam por la oportunidad de llevar a cabo el PSASVP y por sus atinados comentarios en campo. Al Mtro. Serafín Sánchez por su apoyo para la identificación de muestras de sedimentos. Al Mtro. Alberto Villakamel por su apoyo en la identificación de fitolitos. Al Mtro. Jorge Rubio por sus valiosos comentarios. A los Arqueólogos Mijaely Castañón, César Hernández y Fernando Orduña, integrantes del PSASVP, quienes generaron la mayor parte de la información usada para este trabajo. A los dictaminadores anónimos del texto, cuyos comentarios enriquecieron el trabajo. Al personal de la empresa Vía Rápida Poetas quienes prestaron todas las facilidades necesarias para la realización de los trabajos arqueológicos. A todos ellos nuestros más sinceros agradecimientos. Cualquier error u omisión es total responsabilidad de los autores. 


\section{BIBLIOGRAFÍA}

ANSCHUETZ, K., WILSHUSEN, R. \& SCHIECK, C. 2001. An Archaeology of Landscapes: Perspectives and Directions. En Journal of Archaeological Research, (9)2: 152-197, USA.

ARCHIVO GENERAL DE LA NACIÓN (AGN). 1583. GD58. "Hospital de Santa fe. Ordena su señoría que ninguna justicia impida al Hospital de Santa Fe...”. AGN ramo Indios, vol. 2, exp. 629, 633, 146fs.

ARCHIVO GENERAL DE LA NACIÓN (AGN). 1583. GD58. "Al juez repartidor de indios de Tacuba a fin de que socorra con indios al Hospital de Santa Fe...” AGN ramo Indios, vol. 2, exp. 634, 146fs.

ARCHIVO GENERAL DE LA NACIÓN (AGN). 1629. GD58. "Para que Buenaventura de la Cruz, gobernador del Hospital de Santa Fe, saque a los naturales que se huebiesen ido a otra parte..." AGN ramo Indios, vol. 10, exp. 65 fs.

BARNETT, H. 1953. Innovation: the basis of cultural change. series in sociology and anthropology. McGraw-Hill, Los Angeles.

BASALLA, G. 2011. La evolución de la tecnología. Crítica, Barcelona.

BENTLEY, R. \& MASCHNER, H. 2001. Stylistic change as a self-organized critical phenomenon: An archaeological study in complexity. Journal of archaeological method and theory, 8 (1):35-66.

CANTO G. 1986. Proposiciones para el estudio de talleres en producción cerámica. En MANZANILLA L. (ed.) Unidades habitacionales mesoamericanas y sus áreas de actividad. Instituto de Investigaciones Antropológicas, Universidad Nacional Autónoma de México, Serie Antropológicas No. 76, México, Pp.41-58.

CARRASCO, P. 1971. Social Organization of Ancient Mexico. En Handbook of Middle American Indians 10. University of Texas Press, Austin. Pp. 349-374

CERVANTES ROSADO, J. FOURNIER P. \& CARBALlAL M. 2007. La cerámica del Posclásico en la cuenca de México, en MERINO B. \& GARCÍA COOK A. (Coord.) La producción alfarera en el México antiguo, Vol. V, , Colección Científica, No. 508, Instituto Nacional de Antropología e Historia, México, Pp. 277-320.

CHARLTON, T. FOURNIER P. \& OTIS Ch. 2007. La cerámica del periodo Colonial temprano en la cuenca de México, en MERINO B. \& GARCÍA COOK A. (Coord.) La producción alfarera en el México antiguo, Vol. V, Colección Científica, No. 508, Instituto Nacional de Antropología e Historia, México, Pp.429-496.

CHARLTON, T. \& FOURNIER P. 1993. Urban and Rural Dimensions of the Contact Period Central Mexico, 1521-1620. En ROGERS D. \& WILSON S. (eds.) Ethnohistory and Archaeology. Approaches to postcontact change in the Americas. Plenum Press. New York. Pp. 201-220.

CHARLTON, T. \& FOURNIER P. 1997. Patrones arqueológicos de diferencias socio-étnicas en Nueva España. Contrastes urbanos y rurales. Revista Colombiana de Antropología, XXXIII. Pp. 54-83.

COBB, Ch. 2003. Stone Tool Traditions in the Contact Era. Tuscaloosa. University of Alabama Press.

CUSICK, J. 1998. Historiography of Acculturation: An Evaluation of Concepts and their Application in Archaeology. En CUSICK, J. (ed) Studies in Culture Contact: Interaction, Culture Change, and Archaeology. Occasional Paper 25. Center for Archaeological Investigations, Southern Illinois University, Carbondale. Pp. 126-145.

ESCALANTE, P. 2010. Historia mínima: la vida cotidiana. Ciudad de México. El Colegio de México. 
FERNÁNDEZ DÁVILA, E., \& SERAFín, G., 1998. Primer Congreso Nacional de Arqueología Histórica: memoria: Oaxaca, 1996. En Congreso Nacional de Arqueología Histórica, Oaxaca, Instituto Nacional de Antropología e Historia

FOURNIER, P. \& BLACKMAN M. 2007. Producción, intercambio y consumo de lozas vidriadas en Nueva España: Conformación de una base de datos de composiciones elementales mediante INAA. En Cuicuilco. Pp. 123-145.

FOURNIER, P. 1996. Problemáticas metodológicas en el análisis de materiales cerámicos históricos. En Historical Archaeology in Latin America 15. Actas II. Segunda Conferencia Internacional de Arqueología Histórica Americana, edited by Stanley South, pp. 1-11. The University of South Carolina, Columbia.

FOURNIER, P. 1997. Símbolos de la conquista hispana: hacia una interpretación de significados de artefactos cerâmicos del periodo colonial temprano de la Cuenca de México. En Marie Odile Marion (comp.), Simbológicas (pp. 125-138). México, Plaza y Valdés, INAH, CONACYT.

FOURNIER, P. CASTILLO K. BISHOP R. \&BLACKMAN J. 2009. La loza blanca novohispana: tecno-historia de la mayólica en México. En TARGA J. \& FOURNIER P. (Coord.) Arqueología Colonial Latinoamericana, Modelos de estudio. BAR International Series Archeopress, Oxford. Pp. 99-114.

GAZZOLA, J. 2009. Fuentes de abastecimiento de obsidiana en fases tempranas en Teotihuacán, México. Arqueología, (41), 47-63

GLICK, T. 2000. Tecnología. En BERFIELD T. (ed.) Diccionario de Antropología. Siglo XXI, México. Pp. 508-510.

GREENFIELD, P. 1999. Cultural change and human development. En New directions for child and adolescent development, 83:37-59.

GIBSON, Ch. 1986. Los aztecas bajo el dominio español (1519-1810).. Siglo XXI. México.

GONZÁLEZ Y GONZÁLEZ. L. 2009. Viaje por la historia de México. Editorial Clío, Secretaria de Educación Pública. Ciudad de México.

HIRTH, K. \& BRADFORD, A. 2002. Pathways to Prismatic Blades. A Study in Mesoamerican Obsidian Core-Blade Technology. Monograph 45. The Cotsen Institute of Archaeology. University of California. Los Angeles.

HORN, R. 1992. Coyoacán: aspectos de la organización sociopolítica y económica indígena en el centro de México (1550-1650). En Estudios Históricos. INAH, México. Pp. 31-56

KNAPP, B. \& ASHMORE, W. 1999. Archaeological Landscapes: Constructed, Conceptualized, Ideational. En KNAPP, B. \& ASHMORE, W. (eds.) Archaeologies of Landscape: Contemporary Perspectives. Blackwell Publishers, Malden. Pp. 1-30.

LEMONNIER, P. 1986. The Study of Material Culture Today: Toward and Anthropology of Technical Systems. En Anthropological Archeology. 5. Pp. 147-186.

LEÓN PORTILlA, M. 2008. Obras de Miguel León Portilla, Tomos I, II, II. Universidad Nacional Autónoma de México. Ciudad de México

LIGHTFOOT, K. 2005. Indians, Missionaries, and Merchants. The Legacy of Colonial Encounters on the California Frontiers, University of California Press, Berkley, Los Angeles.

LÓPEZ AUSTIN, A. 1996. El pasado indígena. México. COLMEX-FCE-Fideicomiso Historia de las Américas. Ciudad de México.

MARQUINA, I. 1964. Arquitectura prehispánica. Instituto Nacional de Antropología e Historia. Ciudad de México. 
MONTEIRO, J. 2008. Rethinking Amerindian Resistance and Persistence in Colonial Portuguese America. En Paper presented at the conference "Rethinking Histories of resistance in Brazil and Mexico", Manchester.

MUÑIZ, D. ORDUÑNA F. CASTAÑÓN M. \& HERNÁNDEZ C. 2013. Informe Técnico Final del Proyecto de Prospección y Sondeos Arqueológicos en la Súper Vía Poniente (Vía Rápida Poetas), delegaciones Magdalena Contreras, Tlalpan y Cuajimalpa, D.F. Mecanuscrito. Archivo Técnico de la Coordinación Nacional de Arqueología. INAH, Ciudad de México. 201p.

MUÑIZ D. \& SUMANO K. 2017. Cambios y continuidades en el poniente de la cuenca de México durante el periodo del contacto. El caso del salvamento arqueológico del sitio Tarango. En Arqueología Nueva época No. 53, México. Pp. 125-140.

PANICH, L. 2013. Archaeologies of Persistence: Reconsidering the Legacies of Colonialism in Native North America. En American Antiquity. 78 (1): 105-122.

PAREDES B. 1986. La unidad habitacional en la Cuenca de México. Periodo postclásico. En Unidades habitacionales mesoamericanas y sus áreas de actividad, editado por Linda Manzanilla. Instituto de Investigaciones Antropológicas, Universidad Nacional Autónoma de México, Serie Antropológicas No. 76. Ciudad de México. Pp. 221-256.

PASTRANA, A. 1998. La explotación azteca de la obsidiana en la Sierra de las Navajas. Instituto Nacional de Antropología e Historia. Ciudad de México.

PARCERO-OUBIÑA, C. 2011. La construcción del paisaje social en la Edad del Hierro del Noroeste Ibérico. Fundación F. M. Ortegalia. Santiago de Compostela:

PÉREZ TAGLE, G. JiMÉNEZ, S. PÉREZ TAGLE B. 2014. Historia de México. Serie alternativas. Pearson educación de México. Ciudad de México.

PINEDA MENDOZA, R. 2000. Origen, vida y muerte del acueducto de Santa Fe. Universidad Nacional Autónoma de México, México.

PIÑA CHAN, R. 1960. Mesoamérica: ensayo histórico cultural. Instituto Nacional de Antropología e Historia. Ciudad de México.

RAPOPORT, A. 1969. The Meaning of the Built Environment. A Nonverbal Communication Approach. The University of Arizona Press. Tucson.

RAPOPORT, A. 1979. Human Aspects of Urban Form Towards a Man-Environment Approach to Urban Form and Design, Wheaton y Exeter, Londres.

RODRÍGUEZ, A. ÁviLA, E. ANDALUZ, C. GRACIDA E. GARCÍA S. 2014. Historia de México tercer grado. Trillas. Ciudad de México

ROGERS, J. 1990. Objects of Change: The Archaeology and History of Arikara Contact with Europeans. Smithsonian Institution. Washington, D.C.

ROJAS T. 1985. La tecnología agrícola mesoamericana en el siglo XVI. En Historia de la agricultura, época prehispánica-siglo XVI, INAH, México, pp.129-231.

SAHAGÚN, B. 2010. Historia general de las cosas de la Nueva España (Vol. 1). Linkgua digital.

SACKETT, J. 1977. The meaning of style in archaeology: a general model. American Antiquity 42(3):369-380.

SANDERS, W. T. PARSONS, J. R. SANTLEY, R. S. 1979. The basin of Mexico: Ecological Processes in the evolution of civilization. Academic Press, New York. 
SCARAMELLI, F. \& SCARAMELLI K. 2005. The roles of material culture in the colonization of the Orinoco, Venezuela. En Journal of Social Archaeology. 5(1): 135-168.

SCHIFFER, M. \& SKIBO, J. 1987. Theory and experiment in the study of technological change. Current Anthropology 28 (5):595-622.

SCHIFFER, M. SKIBO, J. GRIFFITTS, J. HOLLENBACK, K. \& LONGACARE W. 2001. Archaeology Behavioral Archaeology and the Study of Technology. American Antiquity, 66 (4):729-737.

SCT Secretaría de Comunicaciones y Transportes. Manual para el aprovechamiento del derecho de vía en caminos y puentes de cuota. Disponible en http://www.sct.gob.mx/fileadmin/DireccionesGrales/DGDC/Tramites/manual.pdf Consultado en agosto del 2018

SILLIMAN, S. 2009. Change and continuity, practice, and memory: native American persistence in colonial New England. En American Antiquity 74(2), pp. 211-230.

STEIN, G. 2005. Introduction: The comparative archaeology of colonial encounters. En The Archaeology of Colonial Encounters: Comparative Perspective. STEIN G. (ed). School of American Research Press, Santa Fe. Pp. 1-29.

STARK, M. 1998. Technical choices and social boundaries in material culture patterning: An introduction. En STARK M. (ed) The archaeology of social boundaries. Smithsonian Institution Press. Washington. Pp.1-11.

TILLEY, Ch.. 1994. A phenomenology of landscape: places, paths, and monuments. Oxford, Berg. Oxford.

THOMAS, J. 2001. Archaeologies of place and landscape. En HODDER I. (ed.) Archaeological Theory Today. Polity Press y Blackwell Publisher, Cambridge. Pp. 165-186.

VÁZQUEZ LEÓN, LUIS. 2003. El leviatán arqueológico. Antropología de una tradición científica en México, México, ciesas/Miguel Ángel Porrúa.

VELÁZQUEZ, A. 2007. El trabajo de la concha y los estilos tecnológicos del México prehispánico. En Revista Mexicana de Biodiversidad. 78:77-82.

VEGA SOSA, C. 1975. Forma y decoración en las vasijas de tradición azteca. Colección científica No. 23. Arqueología. Instituto Nacional de Antropología e Historia. Ciudad de México.

WAJARI VELÁSQUEZ F. 2010. La Alfarería entre cultura y naturaleza: Estudio Tecnológico de la cerámica neolítica de la Provincia de Pontevedra. Tesis Doctoral. Universidad de Santiago de Compostela Faculta de Geografía e Historia.

WIESSNER, P. 1983. Style and social information in Kalahari San projectile points. En American Antiquity. 48(2):253-276. 